\title{
Expanding Access to Preventative Dental Care
}

\author{
Jason La Marr Wasden* \\ University of Nevada, USA
}

Submission:January 31, 2018 ; Published: April 06, 2018

*Corresponding author: Jason La Marr Wasden, University of Nevada Las Vegas, USA, Tel: 1-7028952472; Email: Jason.wasden@unlv.edu

\begin{abstract}
Discussion about whether or not mid level providers in dentistry would benefit or detract from the profession is ongoing. While there are strong voices on either side of the argument most states have not yet adopted mid level dental providers. Some models train mid level providers requiring them to obtain an associate degree. Other models allow dental hygienists to obtain further training which allows them to perform the tasks of mid level dental providers. While allowing mid level providers are not a national trend it has seemed to expand access to care in underserved populations in Alaska and Minnesota.
\end{abstract}

Keywords: Access; Preventative Dental Care; Public Policy Entrepreneur; Change Agent;

\section{Introduction}

According to a report titled Mid-Level Dental Providers: Expanding Care to Every Community published by the Kellogg Foundation many people live in pain, miss school or work, and in extreme cases develop life-threatening infections [1]. In April of 2012 the American Heart Association published a statement supporting an association between gum disease and heart disease. The study presented evidence that tooth loss and adverse cardiovascular health were associated with each other. Further research concluded that people with periodontal disease were twice as likely to have heart disease [2]. This finding explains the importance of dental care and how it is linked to an individual's overall long term health [3].

The Kellogg Foundation study found tooth decay was the leading cause of chronic disease among children. Left untreated tooth decay affects the overall future health of the children. These results in increases in chronic illnesses such as life-threatening infections, complications requiring major surgery, increased risk of stroke, heart disease, and diabetes [1]. Our broken system of health care fails one-third of the U.S. population. Many adults and children are going without proper dental care in urban and rural America [1]. They routinely seek dental care in hospital emergency rooms for preventable dental problems. This care is much more expensive and less effective than a regular dental visit [1].

Physicians have increased access to care by introducing mid level providers (nurses/physician assistants) into their practices. Could the Dental Profession increase access by training mid level dental providers? Mid level dental providers are practicing in 50 countries Some of those countries include Great Britain, New Zealand, Australia, Canada, and the U.S. Alaska and Minnesota were the first two states to approve mid level dental providers and more state legislatures are talking about training them to serve underserved populations in their jurisdictions. It raises a question about whether or not the dental hygienist could fill this need.

The dental hygienist is a highly trained dental professional capable of performing many dental procedures currently reserved for Dentists. Some Hygienists have a Master level education. While concerns exist that mid level providers with an associate's degree will not be as concerned with patient safety many studies have proven this is not the case [4]. Considering it takes between four and six years to become a dental hygienist, if the curriculum is reworked in conjunction with the states dental board, and national dental accreditation bodies it could be possible to train dental hygienist to become mid level dental providers. There is already a mid level dental provider (a hygienist) in most dental practices in all 50 states. States just need to allow the training of hygienists to include preventative dental care.

\section{Discussion}

If policy makers choose to allow mid level dental providers to be trained in their states it is important to take into consideration the additional training these providers need, and what the cost of that training would be. The longer it takes to obtain the education and the more expensive the education is, the more money a mid level provider would need to charge, in order to, pay back any debt they incurred. 
Reworking the curriculum for hygienists to become mid level providers is a possibility. It would be necessary to keep the additional training of the hygiene student cost neutral. This could be done by implementing a dental faculty practice to treat patients and generate revenue. Hygienists could rotate through the practice and get the necessary experience they need to practice preventative dental care. Practice revenue and expenses should be separate from the hygiene tuition, and the faculty practice should be run like a private office so students can get the experience of what it is like to be in a private practice.

The cost of education should not increase for the Hygienist, and their income should increase upon graduation if they are allowed to do more complex procedures. If the education requirement is too burdensome, it makes more sense to become a Dentist than a mid level provider. States should not be afraid to create policies to train mid level providers because they fear patient care will be compromised. Some preventative treatment is better than no preventative treatment. Especially, since some of the population is going without dental care in urban and rural settings.

Instead of training hygienists states could choose to train mid level dental providers called dental therapists, dental health aide therapists, and registered or licensed dental practitioners to provide preventative and routine dental services, such as cleanings, fillings, and non-surgical extractions. The students would complete a rigorous education program preparing them for community practice, and obtain an associate's degree. The degree includes a 400 hour internship where they focus on providing preventative services, education, and routine dental care [1]. Some dentists would like to hire mid level providers to work in their practices to expand access to care for Medicare and Medicaid patients.

Supervision will be a vital discussion among dental providers. What should a mid level provider be allowed to do without supervision? What constitutes supervision? Should the supervision come from a Dental Hygienist or a Dentist? Does the supervision need to be in person, or could technology be used to video procedures that need to be supervised. All of these questions should be kept in mind by policy makers when making decisions.

There will be dentists who support mid level providers and dentists who oppose mid level providers, as well as, hygienists who support and hygienists who oppose. What policy makers need to factor in is the need. Are there access issues in their jurisdictions, if so what is the best way to eliminate them? Are dentists currently treating Medicare and Medicaid populations, if not could trained mid level providers help? Many Native American populations are not receiving treatment and mid level providers could be an answer for them to increase access to preventative care. Alaska has had success by employing dental health aide therapists to provide routine preventative and restorative oral health services in tribal health clinics in rural areas of Alaska [1]. Rural areas are not the only areas in need. Urban areas of the country need treatment too. A dentist in Kansas would like to add mid level dental providers to her practice in order to treat a population not being served by dentists in her community [1].

\section{Conclusion}

Mid level providers increase access to dental care in underserved populations. They provide high levels of care to their patients, which increase the health of the patients they treat. The preventative dental treatment has long term benefits those benefits include: a reduction in chronic disease resulting in a healthier taxpaying citizenry. Access to preventative dental care is a major roadblock for many people living in rural locations. A way to overcome that roadblock is to use the policy process to clarify the misunderstandings of the benefits and drawbacks of mid level dental providers. Mid level providers have reduced access issues by providing preventative dental care to patients in areas of the country lacking access to dental providers. State policies preventing mid level dental providers from being trained should be reexamined to allow them to practice in states with access issues. Policy maker's wishing to increase access to dental care should strongly consider allowing the training of mid level dental providers.

Policy makers at the local, state, and federal level will need to collaborate with private for profit, and nonprofit organizations, providers, and citizens to create change. Change will not occur until a public policy entrepreneur is identified who understands how to impact the window of opportunity by combining the policies, politics, and problem streams with social, economic, political, and demographic determinants to lobby state legislative bodies to allow the education and training of mid level dental providers [5]. Once a change agent is identified, and they rally the troops to effect state policy access to underserved populations will increase.

\section{References}

1. Mid-Level Dental Providers: Expanding Care to Every Community.

2. Periodontal Disease and Cardiovascular Disease.

3. Fehrenbach MJ, Herring SW (2012) Illustrated Anatomy of the Head and Neck. ( $4^{\text {th }}$ edn.) St. Louis, MO: Elsevier; pp. 127-151.

4. Shaefer HL, Miller M (2011) Improving access to oral health care services among underserved populations in the US: Is there a role for mid-level dental providers? J Health Care Poor Underserved 22(3): 740-744.

5. Wasden JL (2012) “CHOICES” florida's version of obamacare. 
(C) This work is licensed under Creative
Your next submission with Juniper Publishers will reach you the below assets

- Quality Editorial service

- Swift Peer Review

- Reprints availability

- E-prints Service

- Manuscript Podcast for convenient understanding

- Global attainment for your research

- Manuscript accessibility in different formats

( Pdf, E-pub, Full Text, Audio)

- Unceasing customer service

Track the below URL for one-step submission https://juniperpublishers.com/online-submission.php 